\title{
Experimental Research on the Shear Connectors in Foam Concrete with C-Channel Embedment
}

\author{
Dianzhong Liu ${ }^{1}$ (1), Fayu Wang ${ }^{1 *}$ (1) and Feng Fu ${ }^{1,2}$ (1)
}

\begin{abstract}
In order to improve the longitudinal shear resistance between foam concrete and C-Channels, an investigation is carried out on the shear connectors in foam concrete with cold-formed steel double C-Channels embedment. Twentyfour tests have been carried out in two groups. Two types of connectors: flange connectors and web connectors are installed using self-drilling screws for a rapid construction. The experimental results show that they can effectively improve the longitudinal shear-resist capacity of the concrete. After the experiment, the specimens are dismantled for an interior observation. Based on the observation, the form of damage, the failure mechanism was discovered, and the equation of longitudinal shear capacity was developed. It is concluded that the failure involves independent slippage between two C-Channels and the shear connection fractures. Since the composite structure requires sufficient slip between the two materials, these types of shear connectors will have good enhancement for this type of composite structures subjected to dynamic loads.
\end{abstract}

Keywords: bond-slip, C-Channel, cold-formed steel, foam concrete, shear connector

\section{Introduction}

Cold-formed thin-walled steel is widely used in lightweight steel buildings as the load-bearing structure, enclosure structure and fittings. It provides abundant cross-sectional profiles and sizes available for structural steel designers (Tran and Li 2006). C-shaped steel sections becomes popular in recent years because it has main advantages of lightweight, high-strength, and materialssave (Dawea et al. 2010; Ma et al. 2015). In building construction, it has been made into frames, trusses, beams, and columns as main bearing member (Laím et al. 2013). Also, it has been made into panels, floors, and walls (Wu and Li 2012; Gosowski et al. 2014; Liao et al. 2017; Parnell et al. 2010). Furthermore, new research of cold-formed steel composite structure has embarked (Flores-Johnson and $\mathrm{Li}$ 2012). For instance, load-bearing cold-formed

\footnotetext{
*Correspondence: Fayu Wang@outlook.com

${ }^{1}$ School of Civil Engineering, Jilin Jianzhu University, No. 5088 Xincheng Avenue, Jingyue Economic Development Zone, Changchun, Jilin 130118, People's Republic of China

Full list of author information is available at the end of the article Journal information: ISSN 1976-0485 / eISSN 2234-1315
}

steel walls have been fabricated for testing fire-resistant safety (Chen et al. 2012). They have the advantages such as energy-saving, environmental friendly and rapid construction. But C-channels are still subject to deformation under the condition of fire even if gypsum plasterboards had been added.

Meanwhile, foam concrete has been more widely used for non-structural members in buildings, working as lightweight material for sound barriers, filling for composite members as well as fillers for masonry due to its good thermal insulation and ability to protect against fires (Mydin and Wang 2011). Although foam concrete has been widely used for non-structural purposes, there is an increasing trend for its use in structural support (Mohamad et al. 2014). The compression and flexural resistance of foam concrete have been studied to determine the structural capacity of foam concrete members (Ibrahim et al. 2014). Due to its inherent low density and low strength (Thakrele 2014; Yue and Bing 2015), foam concrete is often used with steel reinforcements or steel composites (Hilal et al. 2015; Ikponmwosa et al. 2014; 
Lim et al. 2014; Tan et al. 2015). Therefore, a new composite structure made of cold-formed thin-walled $\mathrm{C}$ steel embedment and foam concrete is a promising new product. It not only can make use of the good fire resistance feature of foam concrete, but also exhibits excellent seismic performance. This is considered to gain a great application prospect in the multi-story buildings.

The last experimental research of authors (Liu et al. 2017) showed that the longitudinal shear resistance between C-Channel and foam concrete is relative small than other types of composite structural members, due to the low strength of the foam concrete and the smooth surface of double C-Channels. According to this conclusion, further improvement to the performance of two materials in the composite member is imperative. Therefore, in this paper, the research is focused on how to strengthen the shear resistance of composite member.

As we know, web holes of the C-Channels can not only reduce the weight, but also increase the interlocking mechanism between steel and foam concrete. In addition, adding perforated rebars between double C-Channels can further improve the shear bearing capacity (Flores-Johnson and Li 2012). For instance, in studying the bond-slip characteristics between steel and foam concrete, Ramezani et al. (2013) carried out pull-out testing of galvanized steel strips in foam concrete. The bond slip curve shows typical hardening and softening behaviour. In order to improve the anchorage of the steel strips, holes were punched into the steel. The pull-out resistance was found to be directly proportional to the area of the holes which represents more bonding between the steel and the concrete. However, their analysis showed that the steel strip experiences non-uniform strain distribution which results in a larger displacement at the peak force when the bonding increases (by increasing the diameter and circumference of the holes). Furthermore, a series of studies have been done by Moen et al. (2008-2014) also showed that the holes in the column or beam decrease the global buckling load or bending moment. Local buckling is also likely to occur in a member at a hole or between holes. Therefore, taking into account the low strength of foam concrete, if the hole is due to damage the stiffness of C-Channels, it will seriously reduce structural capacity of the composite components.

Overall, though some researches on shear resistance enhancement measures have been conducted, there is no research which is targeted on shear connections for foam concrete with double-limb steel embedment in the past, therefore, the research on the new types of shear connectors was carried by the authors and the results are shown in this paper.

In the research presented in this paper, the density of the foam concrete varies from 800 to $1600 \mathrm{~kg} / \mathrm{m}^{3}$, which provide a good range of compressive and shear strengths. The connectors were placed between the two cold-formed thin-walled $\mathrm{C}$ steel embedment. This type of connectors is different to the normal connectors such as studs, channels and bent-up bars, which are widely used in the past. Its structural form is similar to batten plate or lace bar of the double-limb lattice column in the steel structure, which can effectively improve the overall stability between the two C-Channels. While it is used in the composite structures, it also can effectively improve the shear resistance of the composite members. The positions of connectors are set between flanges or webs. On the other hand, the relative thin wall thickness of C-Channel enables uses the self-drilling screws on the fast installation without drilling or welding. Laboratory push-out tests have been carried out on foam concrete and C-Channels with shear connectors to study the increasing of shear bearing capability.

\section{Test Set Up}

\subsection{Test Arrangement}

Experiments were carried out in Jilin Jianzhu University to determine the effect of different parameters on the shear connection. The dimensions of the concrete specimen and the C-Channels with shear connectors are shown in Fig. 1. As shown in Fig. 1, two types of connectors are used for group E and F, namely, web connectors and flange connectors. Where, web connectors are connected to the web, and the flange connectors are connected to flanges. The thickness of channels used in the tests is $3 \mathrm{~mm}$, with a length of $120 \mathrm{~mm}$ and width of $50 \mathrm{~mm}$ respectively. The concrete block has a rectangular cross section of $440 \times 360 \mathrm{~mm}$ and the embedment depth was chosen as $300 \mathrm{~mm}$. This is because in the past experiments, brittle failures of foam concrete with small embedment depth were observed. 24 specimens were tested. They are divided into Group E (with web connectors) and Group F (with flange connectors) in order to compare with the Group $C$ tests where no shear connectors are used (for the detailed test set up of Group C, please refer to reference Liu et al. 2017). The imbedded depth of all the connectors is $100 \mathrm{~mm}$. Four different densities of foam concrete were studied in each group. The specimens had a density of $800,1000,1200$ and $1600 \mathrm{~kg} / \mathrm{m}^{3}$ respectively. The detailed test arrangements for all three tests are shown in Fig. 1 and Table 1. For each density of the foam concrete, three tests were carried out. This was to ensure the mean value of the result can be taken, for the sake of the accuracy.

The foam concrete was casted with cement, sand, fly ash and foam. All the samples have a fly ash/ cement ratio of $25 \%$ and a water/cement ratio of 0.5 . The strength changed because of the density which 


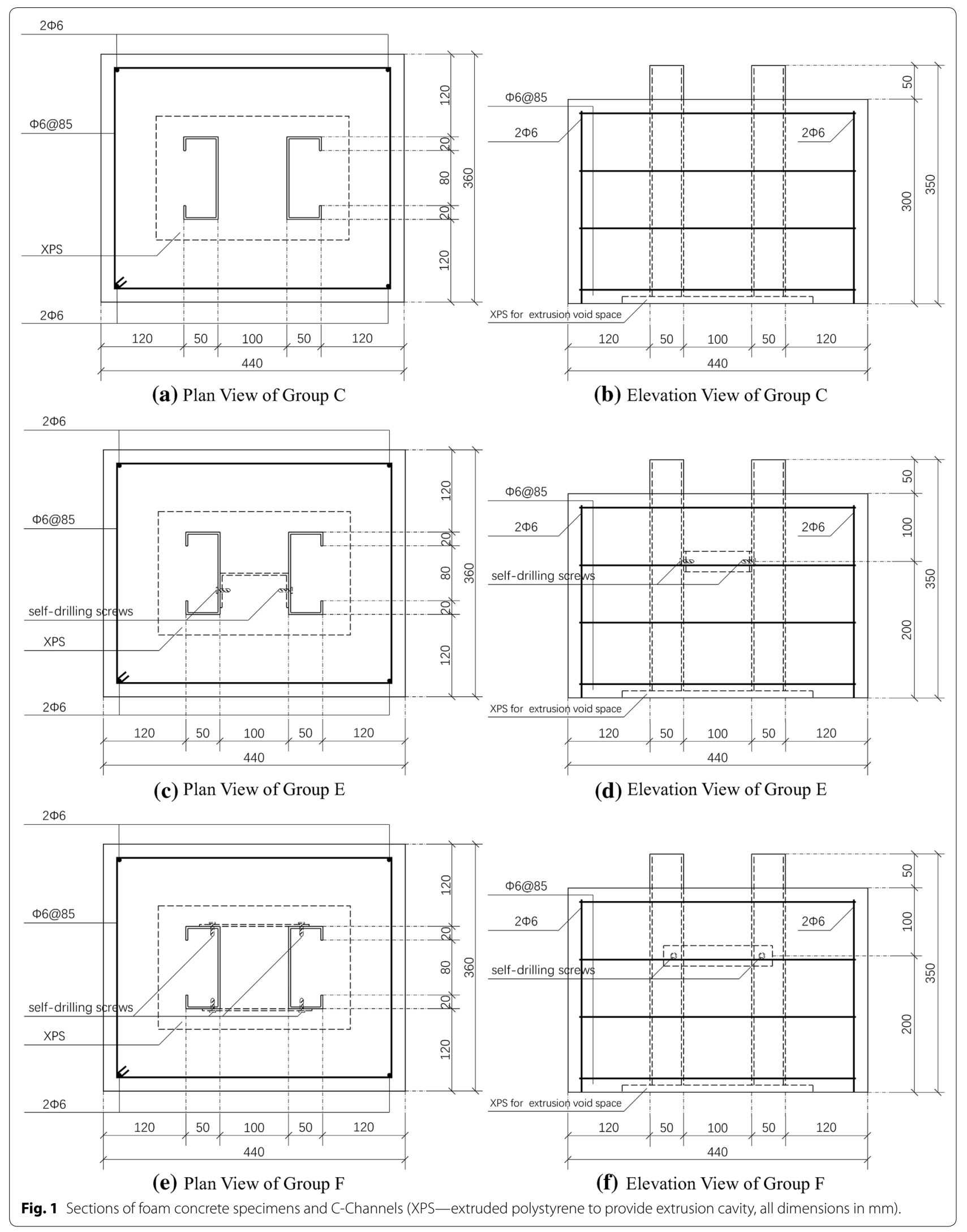


Table 1 Configuration of test specimens.

\begin{tabular}{|c|c|c|c|c|c|}
\hline Group & Specimen number & Depth (mm) & $\begin{array}{l}\text { Foam density (kg/ } \\
\left.\mathrm{m}^{3}\right)\end{array}$ & Measure & Connector size \\
\hline \multirow[t]{4}{*}{ C } & $\mathrm{C} 1-\mathrm{C} 3$ & 300 & 800 & \multirow[t]{4}{*}{ None } & \multirow[t]{4}{*}{ None } \\
\hline & C4-C6 & 300 & 1000 & & \\
\hline & C7-C9 & 300 & 1200 & & \\
\hline & $\mathrm{C} 10-\mathrm{C} 12$ & 300 & 1600 & & \\
\hline \multirow[t]{4}{*}{$E$} & E1-E3 & 300 & 800 & \multirow[t]{4}{*}{ Web connector } & \multirow{4}{*}{$\begin{array}{l}\text { U100 } \times 50 \times 3 \mathrm{~mm} \text { in accord- } \\
\text { ance with } 30 \mathrm{~mm} \text { truncated }\end{array}$} \\
\hline & E4-E6 & 300 & 1000 & & \\
\hline & E7-E9 & 300 & 1200 & & \\
\hline & E10-E12 & 300 & 1600 & & \\
\hline \multirow[t]{4}{*}{$\mathrm{F}$} & F1-F3 & 300 & 800 & \multirow[t]{4}{*}{ Flange connector } & \multirow[t]{4}{*}{$-160 \times 30 \times 3 \mathrm{~mm}$ steel strip } \\
\hline & F4-F6 & 300 & 1000 & & \\
\hline & F7-F9 & 300 & 1200 & & \\
\hline & F10-F12 & 300 & 1600 & & \\
\hline
\end{tabular}

Stirrup has $20 \mathrm{~mm}$ concrete cover, using grade II bar, with diameter of $6 \mathrm{~mm}$, and spacing of $85 \mathrm{~mm}$.

is controlled by changing the volume of the foam. The C-Channels are thin-walled $\mathrm{C}$ type cold formed steel with grade Q235, has an average $330 \mathrm{MPa}$ yield strength. The C-Channel has a cross-sectional size of $\mathrm{C}$ $120 \times 50 \times 20$ with a thickness of $3 \mathrm{~mm}$.

It is worth mentioning that all the connectors were mounted by hexagon flange head drilling screws with tapping screw thread for rapid installation. The outer diameter of the screw is $5 \mathrm{~mm}$ and the effective diameter is $4.30 \mathrm{~mm}$. Three screws were taken for testing and the results showed that the average ultimate shear strength of screws was 708.22 MPa when the pure shear failure occurred. This type of screw only needs to be equipped with an internal six-angle typed bit for the electric drill. C-Channels should be flat before placing foam concrete, see Fig. 2. Also, the properties of the foam concrete of different densities are shown in Table 2.

\subsection{Instrumentations and Testing Procedures}

The specimen with imbedded C-Channels were loaded through vertical compression using hydraulic compression testing machine, see Fig. 3. The foam concrete specimen was sitting on its base. Using the microcontrol system, load increments were set to $15 \mathrm{kN}$ for Group C; and $20 \mathrm{kN}$ for the specimens in Group E and F. The system can also record load-displacement measurements at the required intervals, detect the peak load and switch to a displacement control state to measure the post peak softening response. The rate of the application of the load was $0.2 \mathrm{kN} / \mathrm{s}$ until it reached the peak force. Then the sample was loaded under displacement control by a rate of $0.01 \mathrm{~mm} / \mathrm{s}$.

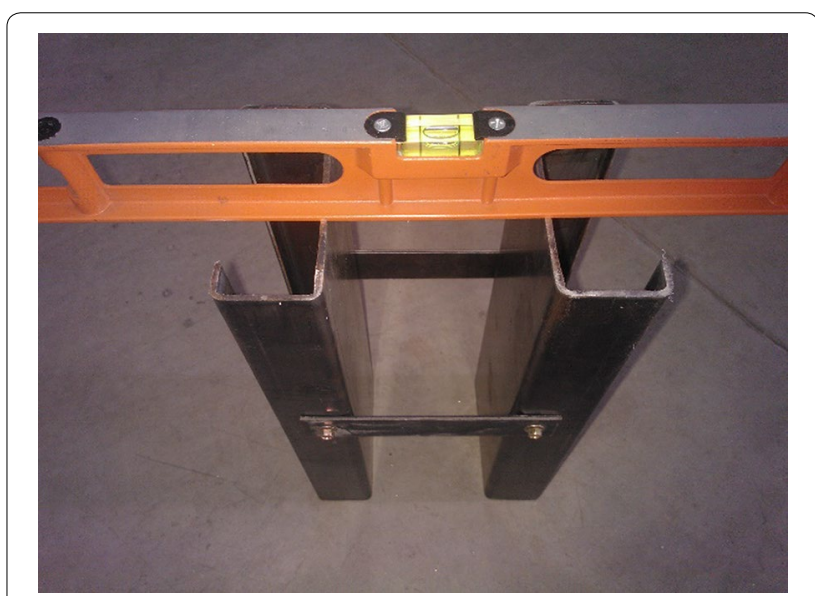

Fig. 2 Connectors installation.

\section{Tests Results}

The vertical force versus vertical displacement plots of different groups are shown in Fig. 4.

\subsection{Result on Shear-Bearing Capacity}

The results are showed in Table 3 and Fig. 5. As expected, the peak forces increase when the density of the foam concrete increases. The peak force increased by using the web connector is about $18.86 \mathrm{kN}$ while that of flange connector is about $18.28 \mathrm{kN}$. This proves that both two types of shear connectors can effectively enhance the longitudinal shear capacity of composite components.

It can be found that, the two types of connectors used in the tests helped to increase almost the same amount of peak forces and behave similarly in foam concrete with 
Table 2 Properties of foam concrete.

\begin{tabular}{|c|c|c|c|c|c|c|}
\hline Test block no. & Density $\left(\mathrm{kg} / \mathrm{m}^{3}\right)$ & $\begin{array}{l}\text { Failure loading } \\
(\mathrm{kN})\end{array}$ & $\begin{array}{l}\text { Compressive } \\
\text { strength (MPa) }\end{array}$ & $\begin{array}{l}\text { Average compressive } \\
\text { strength (MPa) } \\
\text { (SD) }\end{array}$ & $\begin{array}{l}\text { Elastic } \\
\text { modulus } \\
\text { (GPa) }\end{array}$ & $\begin{array}{l}\text { Average elastic } \\
\text { modulus (GPa) } \\
\text { (SD) }\end{array}$ \\
\hline 800-1 & 813 & 224 & 10.0 & & 0.37 & \\
\hline $800-2$ & 807 & 210 & 9.3 & 9.62 & 0.40 & 0.38 \\
\hline $800-3$ & 808 & 216 & 9.6 & $(0.32)$ & 0.38 & $(0.02)$ \\
\hline 1000-1 & 1003 & 297 & 13.2 & & 0.57 & \\
\hline $1000-2$ & 1006 & 304 & 13.5 & 13.57 & 0.58 & 0.55 \\
\hline $1000-3$ & 1007 & 316 & 14.0 & $(0.42)$ & 0.51 & $(0.04)$ \\
\hline $1200-1$ & 1211 & 463 & 18.3 & & 0.90 & \\
\hline $1200-2$ & 1209 & 448 & 17.9 & 18.08 & 0.84 & 0.87 \\
\hline $1200-3$ & 1206 & 481 & 18.1 & $(0.18)$ & 0.87 & $(0.03)$ \\
\hline 1600-1 & 1604 & 552 & 24.5 & & 1.50 & \\
\hline $1600-2$ & 1598 & 518 & 23.0 & 23.68 & 1.47 & 1.49 \\
\hline $1600-3$ & 1596 & 528 & 23.5 & $(0.78)$ & 1.50 & $(0.02)$ \\
\hline
\end{tabular}

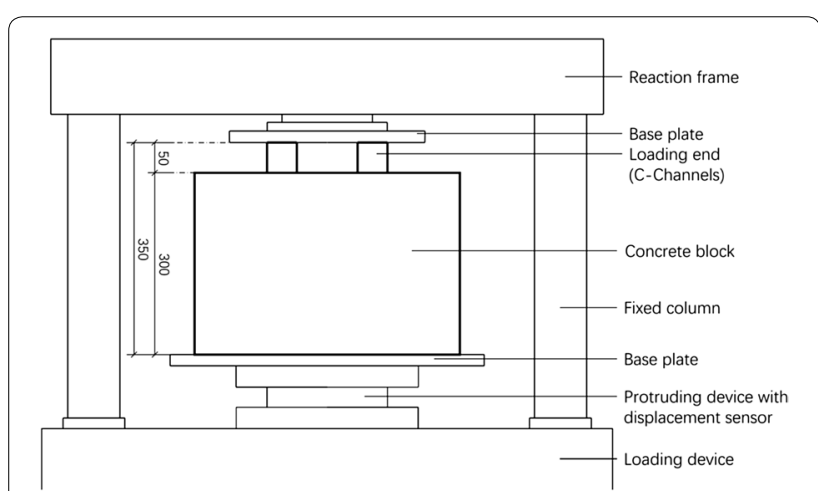

Fig. 3 Test setup (unit: $\mathrm{mm}$ ).

different densities. This is inconsistent with other related research such as the experimental results of Allahyari's et al. (2018) and Huo's et al. (2018). As we know, the longitudinal shear capacity of the connectors depends on the strength of the components such as the connectors and concrete. The specific calculation methods can be classified into two categories.

In most cases, shear connectors in composite components are designed to have sufficient strength, therefore, the crushing or split of the concrete is one of the major failure modes. Local concrete will be crushed or be split. Therefore, the increase of shear resistance is proportional to the compression area, shear strength, and elastic modulus of concrete. For this experiment, the equation can be as follow:

$$
V_{1}=\alpha A_{s} \sqrt{E_{c} f_{c}}
$$

where $V$ is the value of increased longitudinal shear force by a connector; $\alpha$ is the bearing capacity coefficient of shear connection; $A_{s}$ is the cross-sectional area of the connector; $E_{c}$ is the elastic modulus of foam concrete; $f_{c}$ is the compressive strength of foam concrete. (For this calculated value, cube compressive strength of concrete is used in Chinese codes; cylindrical compressive strength of concrete is used in codes of United States, Canada and Europe.)

On the other hand, when the strength of the connector is not sufficient, failure will happen on connectors. The improvement of longitudinal shear capacity depends on the material of connectors. The failure of shear connectors often occurs at the location where the self-drilling screws are located. Because these two types of shear connectors provide the mechanical interlocking and transmitting the longitudinal shear between the C-Channels and foamed concrete through screws. Therefore, the increased shear by a connector can be calculated from

$$
V_{2}=\beta n \frac{\pi d_{e}^{2}}{4} f_{s v}
$$

where $V$ is the value of increased longitudinal shear force by a connector; $\beta$ is the bearing capacity coefficient of shear connection; $n$ is the number of self-drilling screws setting on one shear connector; $d_{e}$ is the effective diameter of self-drilling screw; $f_{s v}$ is the shear strength of selfdrilling screw.

In the calculation, $V$ should take the minimum value of $V_{1}$ and $V_{2}$. However, the experimental results are probably consistent with Eq. 2 . It is necessary to further investigate the failure mechanism of specimens to confirm this hypothesis. 


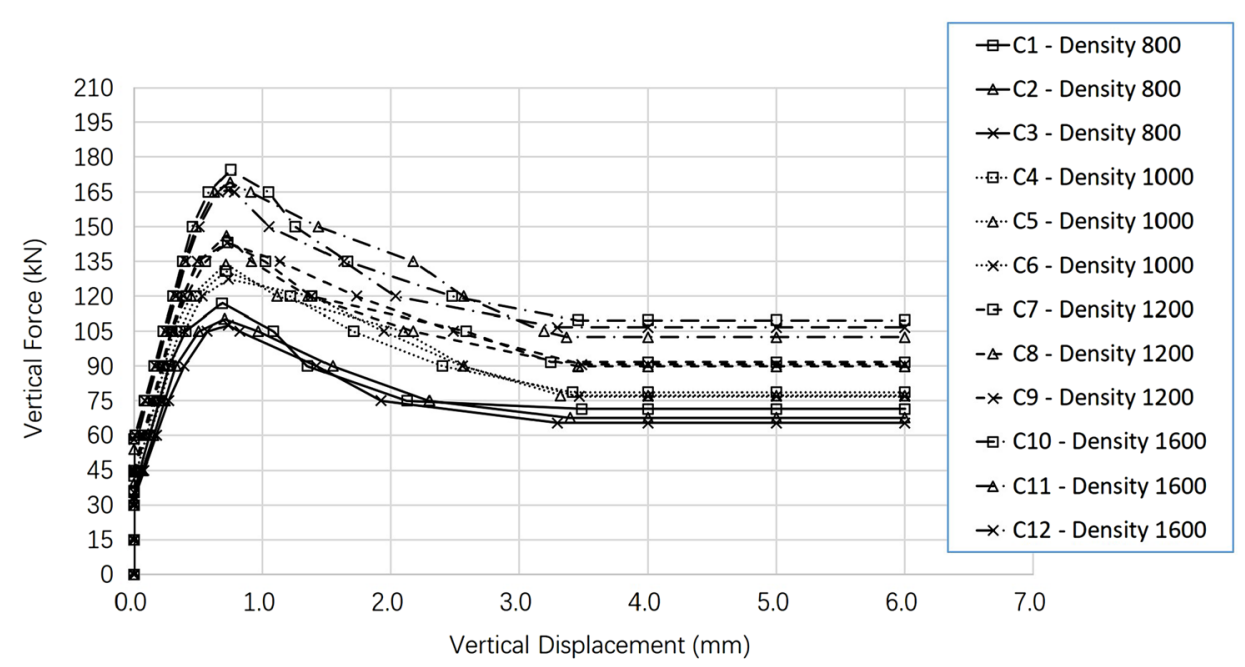

(a) Force Displacement Plot of Group C Specimens

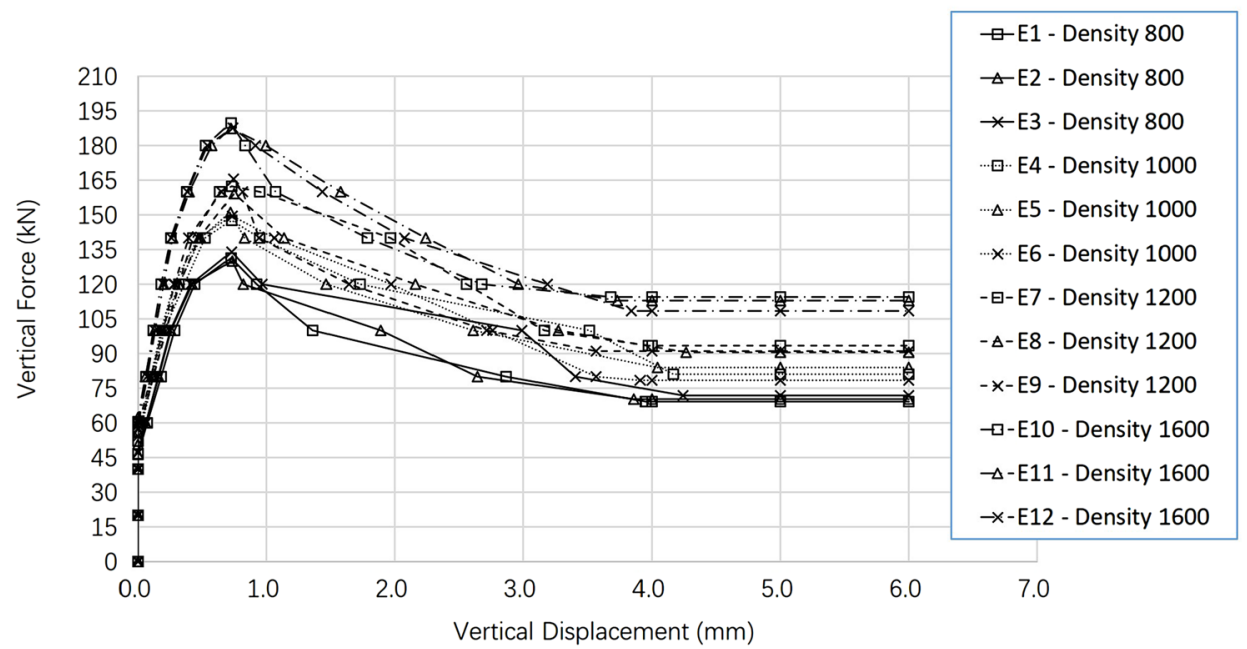

(b) Force Displacement Plot of Group E Specimens

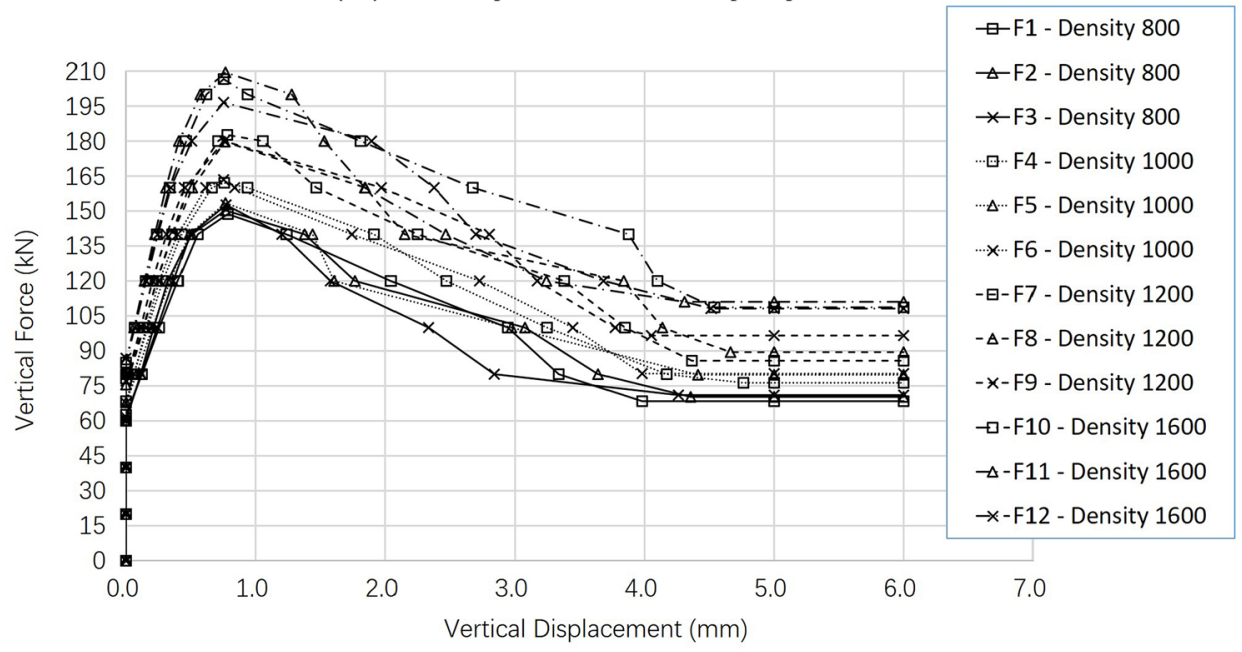

(c) Force Displacement Plot of Group F Specimens

Fig. 4 Force displacement plot of all specimens. 
Table 3 Peak forces of test specimens.

\begin{tabular}{|c|c|c|c|c|c|c|}
\hline \multirow[t]{2}{*}{ Concrete density $\left(\mathrm{kg} / \mathrm{m}^{3}\right)$} & \multicolumn{6}{|c|}{ Peak vertical force (kN) } \\
\hline & Group C & Average value & Group E & Average value & Group F & Average value \\
\hline & 116.92 & & 131.49 & & 148.67 & \\
\hline \multirow[t]{3}{*}{800} & 110.29 & 111.61 & 130.05 & 131.83 & 150.30 & 150.54 \\
\hline & 107.61 & & 133.94 & & 152.64 & \\
\hline & 130.79 & & 147.66 & & 162.08 & \\
\hline \multirow[t]{3}{*}{1000} & 133.79 & 130.67 & 151.10 & 149.41 & $153.41^{*}$ & 162.77 \\
\hline & 127.44 & & 149.47 & & 163.46 & \\
\hline & 143.31 & & 162.33 & & 182.62 & \\
\hline \multirow[t]{3}{*}{1200} & 146.24 & 144.18 & 159.16 & 162.32 & 179.68 & 180.78 \\
\hline & 142.99 & & 165.47 & & 180.03 & \\
\hline & 174.52 & & 189.86 & & 206.65 & \\
\hline \multirow[t]{2}{*}{1600} & 169.27 & 169.94 & 187.37 & 188.28 & 209.46 & 204.25 \\
\hline & 166.02 & & 187.62 & & 196.64 & \\
\hline Average value & 139.10 & & 157.96 & & 175.66 & \\
\hline
\end{tabular}

Average increase of shear resistance by a web connector is $157.96 \mathrm{kN}-139.10 \mathrm{kN}=18.86 \mathrm{kN}$.

Average increase of shear resistance by a flange connector is $(175.66 \mathrm{kN}-139.10 \mathrm{kN}) / 2=18.28 \mathrm{kN}$.

*Denotes invalid data because of fast loading, this data is not involved in subsequent analysis.

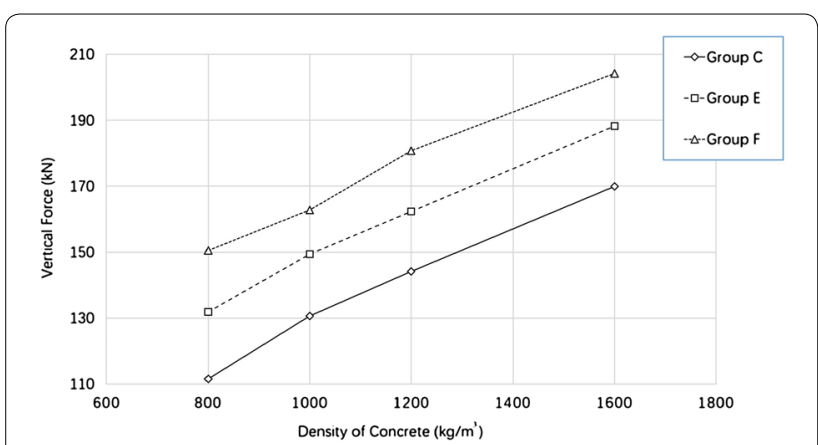

Fig. 5 Peak force for different groups of specimens.

\subsection{Interior Observation of Specimens}

As it shown in Fig. 6, the specimens were dismantled after the tests, which demonstrate the failure modes of both the flange connectors and web connectors. From the observation of specimens' surfaces, it would be found that specimens of Group E and Group F had the same global failure mode as specimens of Group $C$, which is so-called Mode 1A failure (Liu et al. 2017). Mode 1A involves the bond failure at the interface between the steel and foam concrete on the outside perimeter, but not interior surface of the C-Channel. There is a local splitting occurs in the foam concrete between the steel flanges. Then the concrete blocks were smashed, and they were internally observed as Fig. 6 . It could be seen that the self-drilling screws had been sheared off.

It is observed that the shear connectors damaged in the mode of both Group E and Group F specimens were all pure shear failure of self-drilling screws, the fracture of screws occurred on contact surfaces between C-Channels and shear connectors. This means very little end slip between shear connectors and the foam concrete while they stayed in the position when the failure occurred.

\subsection{Modes of Failure}

Compared the results of this experiment with another paper of the authors (Liu et al. 2017), three failure modes of Group E and F specimens can be deduced.

1. Mode 1B Mode 1A failure plus shear failure of connectors

Mode 1A is the most typical failure mode of foam concrete with C-Channel embedment, such as the specimens of Group C. This involves bond failure at the interface between the steel and foam concrete on the outside perimeter, but not on the inside perimeter of the C-Channel. In developing a mechanism of failure in Mode 1A, failure occurs in the foam concrete between the steel flanges because of the brittleness and low strength of foam concrete. Meanwhile, the shear connectors of Group E and F have been completely destroyed in the process of loading. From above analysis, the shear capacity is provided by connector changes at each stage during the loading. But the maximum shear force that a shear connector can bear is reached before the moment that failure of the shear connectors is occurring. 


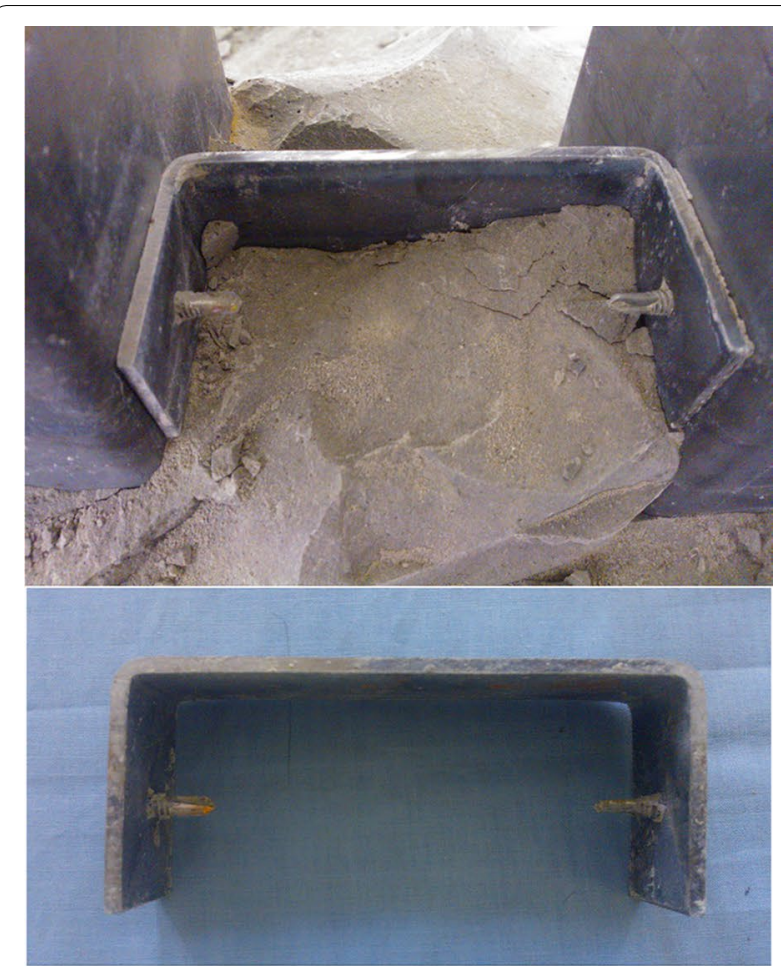

(a) Failure Mode of Web Connectors
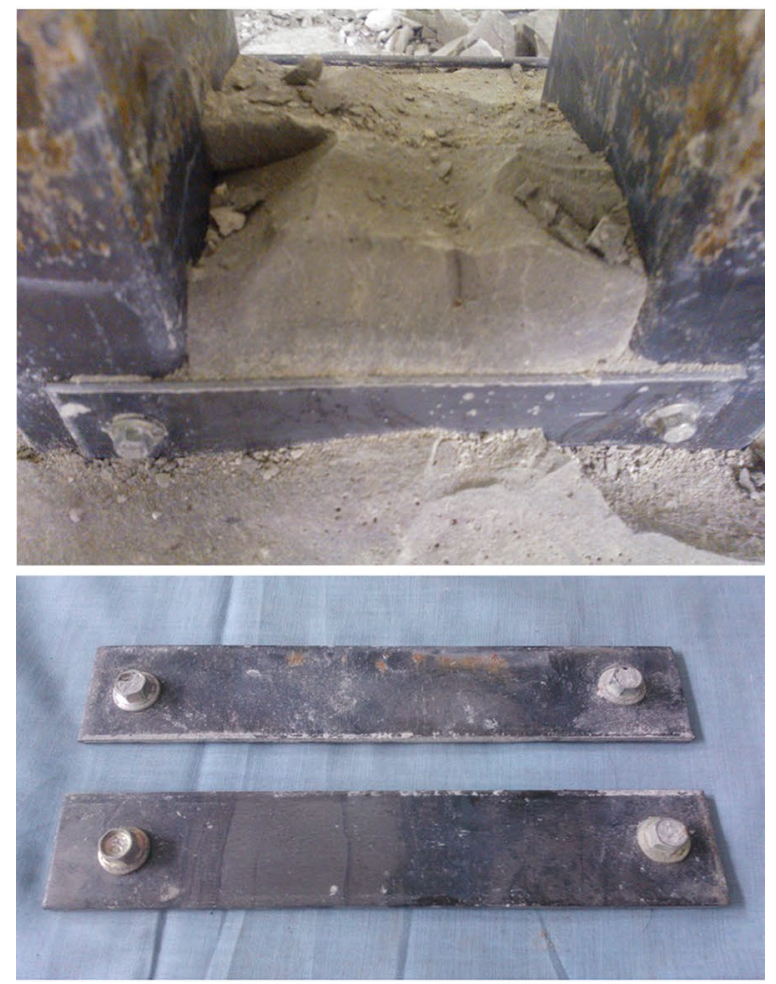

(b) Failure Mode of Flange Connectors

Fig. 6 Failure modes of shear connectors.
2 Mode 2, shear connectors and concrete block between the two C-Channels slip with C-Channels together no fracture of shear connectors.

3 Mode 3, large area concrete block extrusion Based on the experimental observations, Modes 2 and 3 have not been observed for a large range of densities and strengths of the foam concrete that were tested due to the small strength of the screws used in this experiment. But it can be speculated that when the shear connectors are strong, the connections will not fail. Therefore, the connectors will split the foam concrete which will cause Mode 2 (shear connectors and concrete block between the two C-Channels slip with C-Channels together) and Mode 3 (foam concrete occurs large area brittle failure). The rational inference of Mode 2 is verified in another experiment of authors.

Based on the specimen of Group F, another test with two additional flange connectors are added. The vertical spacing of connectors is $100 \mathrm{~mm}$. This causes that Mode 1A of bond failure plus shear failure of connectors occur in the upper part of specimens and Mode 2 occurs in the lower part of specimens with the density of $800 \mathrm{~kg} / \mathrm{m}^{3}$, see Fig. 7. This indicates that when the strength of concrete is insufficient and/ or the connecting strength between connectors and C-Channels is too strong, Mode 2 and Mode 3 may occur.

\subsection{Force Displacement Relationship of Shear Connections} After statistically analyse of the experimental data on the failure mode of shear connectors, a force-displacement curve of the shear connections was developed by the authors, it can be divided into 5 phases as same as bond-slip relationship. The different stages of the force development in the shear connectors during the loading process in these experiments have been analytically interpreted as follows Fig. 8 (Liu et al. 2017):

\section{Vertical increase (OA segment)}

The applied load was primarily resisted by the chemical bonding force and the shear connectors were not damaged, the full shear interaction between the foam concrete and they could be the C-Channels can be presumed. The presence of the connectors increased the shear interaction between the steel and the foam concrete. Thus, the specimens with connectors can resist more load than those of Group $\mathrm{C}$ in this process. Its specific performance is that the ordinates of the A points in Group E and F are slightly larger than that in Group C.

2. Linear increase (AB segment), 


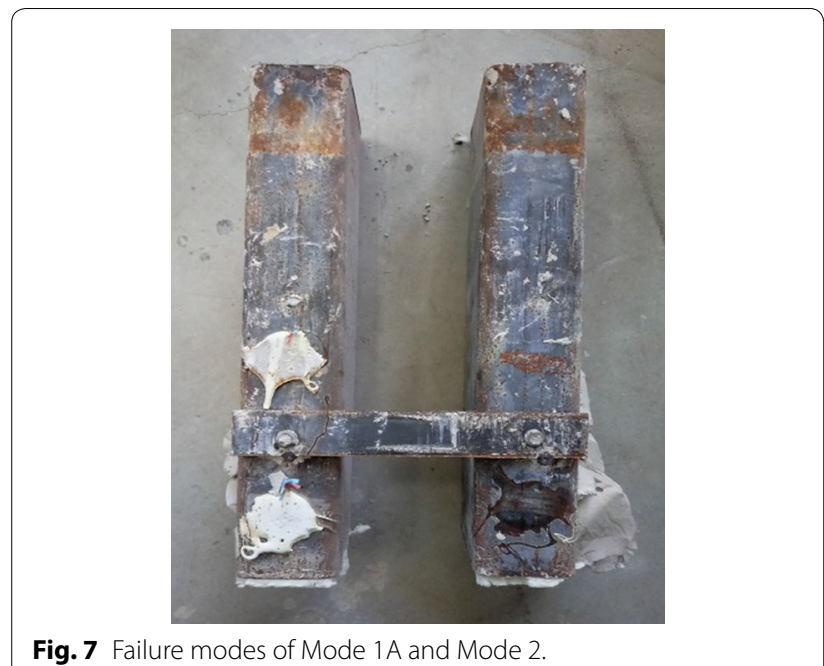

Fig. 7 Failure modes of Mode 1A and Mode 2

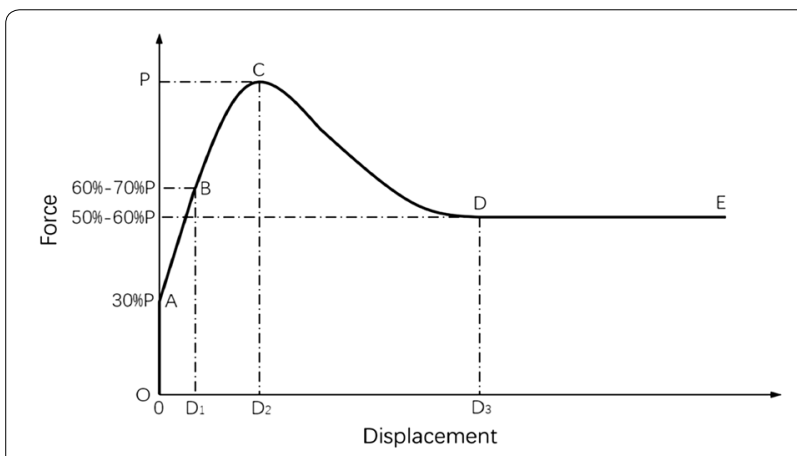

Fig. 8 Force and displacement behaviour curve

3. Upward slope of curve (BC segment)

Shear connectors exhibited same property in these two segments. When the end slip between the $\mathrm{C}$-Channels and the foam concrete are noticeable, the joints were shearing the concrete block that provided a huge mechanical interlocking to prevent the relative slip between $\mathrm{C}$-Channels and foam concrete. This force was transferred to steel by self-drilling screws, which effectively increased the shear resistance of the components. The increased slope of $A B$ segment shows that the bearing force of connectors was increasing gradually. And the peak force is also increased. When the shear stresses of the self-drilling screws reached their ultimate shear strength, screws fail make the connectors stop moving.

4. Declination (CD segment)

After the self-drilling screws fractures, the shear connectors failed. However, screw caps of Group $\mathrm{E}$ and screw stems of Group F were still embedded in the concrete and they kept sliding along with the
C-Channels. The parts of these screws were like minor shear connectors until they were secondly cut. This is why the data of specimens with shear connectors is more irregular than it of Group $\mathrm{C}$ during this process.

5. Plateau (DE segment)

Shear connectors did not have any residual effect in this segment. There was only frictional resistance between the C-Channels and the foam concrete.

\section{Calculation of Peak Force for Different Modes of Failure}

The method to calculate the peak force for all 3 modes is developed here; it was assumed that the mobilized shear stress between C-Channels and foam concrete was uniformly distributed along the failure surfaces, plus the increased shear resistance by connectors.

The peak force can be calculated from

$$
P=2 \alpha f_{c v} A_{c} d+\beta n_{1} n_{2} \frac{\pi d_{e}^{2}}{4} f_{s v}
$$

where $P$ is the peak vertical force; $\alpha$ is the steel-concrete interface coefficient; $f_{c v}$ is the shear strength of the foam concrete; $A_{c}$ is the perimeter of failure section between the steel (ignore connectors) and concrete; and $d$ is the depth of the steel C-Channel in the concrete block; $\beta$ is the bearing capacity coefficient; $n_{1}$ is the number of shear connectors; $n_{2}$ is the number of self-drilling screws setting on one shear connector; $d_{e}$ is the effective diameter of self-drilling screw; $f_{s v}$ is the shear strength of self-drilling screw. $\beta$ is superimposed coefficient of shear connection. The peak force for each channel is multiplied by 2 for two channels.

The previous calculation results showed that $\alpha=1$ when the failure occurs in the concrete; $\alpha=0.7$ between the steel and foam concrete that are the most accurate values. In addition, $\beta=0.92$ of web connector and $\beta=0.89$ of flange connector can be calculated for Modes 1 and $1 \mathrm{~A}$ from the increment of peak forces by the two types of shear connectors. And it can take a value of 0.9 in order to facilitate calculation. For Modes 2 and 3, the peak force only depends on the shear strength of foam concrete so that the $\beta=0$ of these two cases.

Comparisons between measured and calculated peak vertical forces with different densities of foam concrete have been shown in Table 4 and Fig. 9.

A line which shows the equal values of the calculated and observed data is drawn on each graph for comparison purposes. Point on or close to the lines represent a good match between the calculated and observed data.

From Eq. 3 it is seen that to increase the diameter and number of self-drilling screws, or switch to higher shear 
Table 4 Comparisons between calculated and measured peak vertical forces.

\begin{tabular}{|c|c|c|c|c|c|c|c|c|c|c|}
\hline \multirow[t]{2}{*}{$\begin{array}{l}\text { Concrete density } \\
\left(\mathrm{kg} / \mathrm{m}^{3}\right)\end{array}$} & \multirow[t]{2}{*}{$a$} & \multirow[t]{2}{*}{$\begin{array}{l}\text { Shear strength } \\
\text { of concrete (kPa) }\end{array}$} & \multirow[t]{2}{*}{$\beta$} & \multirow[t]{2}{*}{$\begin{array}{l}\text { Shear strength } \\
\text { of screw (MPa) }\end{array}$} & \multicolumn{3}{|c|}{$\begin{array}{l}\text { Calculated peak force }(\mathrm{kN}) \\
\text { group }\end{array}$} & \multicolumn{3}{|c|}{$\begin{array}{l}\text { Measured peak force } \\
(\mathrm{kN}) \text { group }\end{array}$} \\
\hline & & & & & $C$ & $E$ & $F$ & $C$ & $E$ & $F$ \\
\hline 800 & 0.7 & 750 & 0.9 & 708 & 111 & 130 & 148 & 112 & 132 & 151 \\
\hline 1000 & 0.7 & 850 & 0.9 & 708 & 126 & 145 & 163 & 131 & 149 & 163 \\
\hline 1200 & 0.7 & 950 & 0.9 & 708 & 140 & 159 & 177 & 144 & 162 & 181 \\
\hline 1600 & 0.7 & 1200 & 0.9 & 708 & 178 & 197 & 215 & 170 & 188 & 204 \\
\hline
\end{tabular}

strength screws can further improve the function. But the capacity enhancement is limited by the strength of the foam concrete, such as brittle failure of the concrete which are failure of Modes 2 and 3.

\section{Further Discussion}

The superposition of the longitudinal shear capacity of the shear connector and natural bonding function provide longitudinal shear resistance of composite members, but they are relatively independent. However, considering the superposition effect of the two should depend on the shear connectors because the natural bonding function between cold-formed thin-walled $\mathrm{C}$ steel and foam concrete is not changed by shear connectors. The main influence factor is the buried depth of shear connector. For instance, when the shear connector buried depth is too small and near to the loading end, it will be premature to reach the ultimate shear capacity. That means the failure of shear connectors shall occur in the increasing segment of natural bond-slip. Otherwise the shear connectors will fail in the descending phase of natural bondslip. Therefore, the maximum value will happen on the situation that the two peaks overlap. It's best to make the

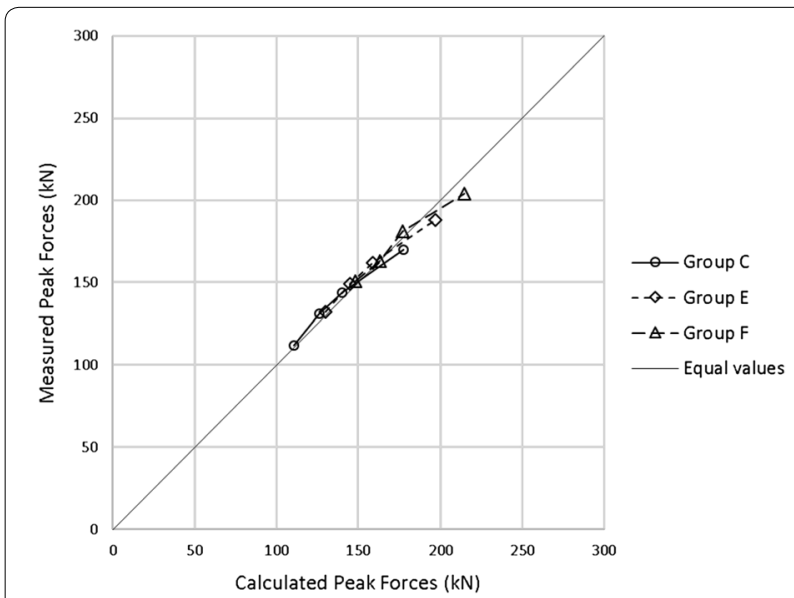

Fig. 9 Comparison between measured and calculated peak vertical forces. self-drilling screws are being cut off as the same displacement as the peak force of natural bond.

Composite member using shear connectors should have a feasible spacing of shear connectors. When the spacing is too large, the shear of connectors cannot be effectively transferred along buried depth of C-Channels. And shear connectors will fail consecutively. This will make the shear connectors only work locally but cannot effectively improve the shear capacity of the whole composite structure. However, if the spacing is too small, it will increase the damage of foam concrete which will result foam concrete brittle failure.

The failure modes summarized in this paper can also explain the above inferences. Although Mode 2 and 3 did not occur, however, if Mode 3 exists, add shear connectors won't make difference. Meanwhile, Mode 2 is likely to be the limited in increasing the shear capacity by connectors. Therefore, $\beta=0$ is chosen for these two modes. All these indicate that the shear connectors cannot be added indefinitely. When the shear capacity of the connectors increases to a certain value, then Mode 2 or Mode 3 may occur, the shear resistance of composite members will not increase with the number and strength of shear connectors. If the flange connector is set too much, the area of the connector will not be ignored. Considering the interface coefficient between steel and concrete is less than 1 . It is possible to reduce the original shear capacity when Mode 2 occurs. This means that $\beta$ needs to be calculated by less than 0 , and the shear capacity of composite members is lower than that of the Mode 2 without connectors.

Combined with the failure mode of shear connectors in this test and the superimposed effect of shear connective function developed in this paper, $200 \mathrm{~mm}$ as reasonable spacing of the shear connector in setting up. When the composite member in the structure is used as the main load-bearing member, the spacing should be properly selected. But its minimum should not be less than $100 \mathrm{~mm}$.

The test results of the web connector and flange connector are compared. Although their failure mechanisms are the same, the flange connector does not cause 
eccentricity and two connectors at same buried depth can be used. On the other hand, flange connector in the manufacture and installation process is more economical applicability.

In addition, though the coefficient $\beta=0.9$ can well agree with the measured data, it was calculated by the limit failure mode. It should be designed according to the yield strength of self-drilling screws with considering safety factor. So $\beta=0.5$ can be used as a design ratio for practical application.

\section{Conclusions}

Based on the experimental tests and theoretical analysis, the following conclusions can be made:

- Both two types of shear connectors can effectively improve the shear resistance of composite members. Each type of connector can further enhance shearing force of about $18 \mathrm{kN}$ because their mechanism is same. But the flange connection has better performance than the web connection due to the difference of the setting position.

- When shear connectors are not strong enough to crash the foam concrete block, the enhanced longitudinal shear force of the composite members is determined by the strength of the connections.

- According to the failure modes of shear connectors, a formula for improving shear force is developed.

- Low strength of foam concrete tends to lead to brittle failure of the concrete. The reasonable setting spacing of shear connectors should be considered. But this still needs further experimental verification. For example, by setting up equal number but different spacing shear connectors.

- A reasonable shear spacing is recommended for this type of structure

\section{Authors' Contributions}

$\mathrm{DL}$ and FW designed the manuscript; FW and FF wrote the manuscript; DL and FF reviewed the manuscript; FW and FF revised the final manuscript. All authors read and approved the final manuscript.

\section{Author details}

${ }^{1}$ School of Civil Engineering, Jilin Jianzhu University, No. 5088 Xincheng Avenue, Jingyue Economic Development Zone, Changchun, Jilin 130118, People's Republic of China. ${ }^{2}$ School of Mathematics, Computer Science \& Engineering, Department of Civil Engineering, City, University of London, Northampton Square, London EC1V OHB, United Kingdom.

\section{Acknowledgements}

The authors gratefully acknowledge funding from the National Natural Science Foundation of China. Project name: Failure mechanism research for lightweight steel and foam concrete composite structure. Approval number: 51378238 .

\section{Publisher's Note}

Springer Nature remains neutral with regard to jurisdictional claims in published maps and institutional affiliations.

Received: 2 December 2017 Accepted: 2 May 2018

Published online: 26 July 2018

\section{References}

Allahyari, H., Nikbin, I. M., Rahimi, S., \& Heidarpour, A. (2018). A new approach to determine strength of Perfobond rib shear connector in steel-concrete composite structures by employing neural network. Engineering Structures, 157, 235-249.

Chen, W., Ye, J., Bai, Y., \& Zhao, X. L. (2012). Full-scale fire experiments on loadbearing cold-formed steel walls lined with different panels. Journal of Constructional Steel Research, 79(2012), 242-254.

Dawea, J. L., Liu, Y., \& Li, J. Y. (2010). Strength and behaviour of cold-formed steel offset trusses. Journal of Constructional Steel Research, 66(2010), $556-565$.

Flores-Johnson, E. A., \& Li, Q. M. (2012). Structural behaviour of composite sandwich panels with plain and fibre-reinforced foamed and corrugated steel faces. Composite Structures, 94(5), 1555-1563.

Gosowski, B., Kubica, E., \& Rykaluk, K. (2014). Analysis of laterally restrained cold-formed C-shape purlins according to Vlasov theory. Archives of Civil and Mechanical Engineering, 15(2014), 456-468.

Hilal, A. A., Thom, N. H., \& Dawson, A. R. (2015). The use of additives to enhance properties of pre-formed foamed concrete. International Journal of Engineering and Technology, 7(4), 286-293.

Huo, J., Wang, H., Zhu, Z., Liu, Y., \& Zhong, Q. (2018). Experimental study on impact behavior of stud shear connectors between concrete slab and steel beam. Journal of. Structural Engineering, 144(2), 04017203.

Ibrahim, W., Jamaluddin, N., Irwan, J. M., Ramadhansyah, P. J., \& Suraya Hani, A. (2014). Compressive and flexural strength of foamed concrete containing polyolefin fibers. Advanced Materials Research, 911, 489-493.

Ikponmwosa, E., Falade, F., Fapohunda, C., Akinniyi, T., \& Olori, K. (2014). Effect of foam concentration on structural characteristics of steel reinforced aerated concrete beams. Pacific Journal of Science and Technology, 15(1), 32-46.

Laím, L., Rodrigues, J. P. C., \& da Silva, L. S. (2013). Experimental and numerical analysis on the structural behaviour of cold-formed steel beams. ThinWalled Structures, 72(2013), 1-13.

Liao, F., Wu, H., Wang, R., \& Zhou, T. (2017). Compression test and analysis of multi-limbs built-up cold-formed steel stub columns. Journal of Constructional Steel Research, 128(2017), 405-415.

Lim, S., Tan, C., Zhao, X., \& Ling, T. (2014). Strength and toughness of lightweight foamed concrete with different sand grading. KSCE Journal of Civil Engineering. https://doi.org/10.1007/s12205-014-0097-y.

Liu, D., Wang, F., Fu, F., \& Wang, H. (2017). Experimental research on the failure mechanism of foam concrete with C-Channel embedment. Computers and Concrete, 20(3), 263-273.

Ma, W., Becque, J., Hajirasouliha, I., \& Ye, J. (2015). Cross-sectional optimization of cold-formed steel channels to Eurocode 3. Engineering Structures, 101(2015), 641-651

Moen, C. D., \& Schafer, B. W. (2008). Experiments on cold-formed steel columns with holes. Thin-walled Structures, 46(10), 1164-1182.

Moen, C. D., \& Schafer, B. W. (2009). Elastic buckling of cold-formed steel columns and beams with holes. Engineering Structures, 31(12), 2812-2824.

Moen, C. D., Schudlich, A., \& von der Heyden, A. (2013). Experiments on cold-formed steel C-section joists with unstiffened web holes. Journal of Structural Engineering, 139(5), 695-704.

Mohamad, N., Khalil, A. I., Abdul Samad, A. A., \& Goh, W. I. (2014). Structural behavior of precast lightweight foam concrete sandwich panel with double shear truss connectors under flexural load. ISRN Civil Engineering. https://doi.org/10.1155/2014/317941.

Mydin, M. A. O., \& Wang, Y. C. (2011). Elevated-temperature thermal properties of lightweight foamed concrete. J. Construction and Building Materials, 25, 705-716. 
Parnell, R., Davis, B. W., \& Xu, L. (2010). Vibration performance of lightweight cold-formed steel floors. Journal of Structural Engineering, 136(2010), 645-653.

Ramezani, M., Vilches, J., \& Neitzert, T. (2013). Pull-out behavior of galvanized steel strip in foam concrete. International Journal of Advanced Structural Engineering, 5(1), 24.

Smith, F. H., \& Moen, C. D. (2014). Finite stripe lastic buckling solutions for thinwalled metal columns with perforation patterns. Thin-walled Structures, 79, 187-201.

Tan, C. S., Lee, Y. L., Mohammad, S., Lim, S. K., \& Lee, Y. H. (2015). Interaction between cold-formed steel and lightweight foamed concrete with various cement content. Malaysian Journal of Civil Engineering, 27(1), 115-127.
Thakrele, M. H. (2014). Experimental study on foam concrete. International Journal of Civil, Structural, Environmental and Infrastructure Engineering Research and Development, 4(1), 145-158.

Tran, T., \& Li, L. (2006). Global optimization of cold-formed steel channel sections. Thin-Walled Structures, 44(2006), 399-406.

Wu, D. P., \& Li, C. Y. (2012). Study of stability under axial pressure of opened cold-formed thin-wall steel with batten plates. Journal of Wuhan University of Technology, 11, 104-108.

Yue, L., \& Bing, C. (2015). New type of super-lightweight magnesium phosphate cement foamed concrete. Journal of Materials in Civil Engineering. https://doi.org/10.1061/(ASCE)MT;1943-5533.0001044,04014112.

\section{Submit your manuscript to a SpringerOpen ${ }^{\circ}$ journal and benefit from:}

- Convenient online submission

- Rigorous peer review

- Open access: articles freely available online

- High visibility within the field

- Retaining the copyright to your article

Submit your next manuscript at springeropen.com 